\title{
O DIREITO FUNDAMENTAL À ÁGUA DECORRENTE DO REGIME DEMOCRÁTICO E DOS PRINCÍPIOS CONSTITUCIONAIS
}

\section{RESUMO:}

\section{João Hélio Ferreira Pes ${ }^{1}$}

Este trabalho analisa o reconhecimento da fundamentalidade do direito de acesso à água a partir do regime democrático adotado pelo Estado brasileiro e dos princípios constitucionais. Para enfrentar o problema proposto, sobre a possibilidade de reconhecer como fundamental o direito de acesso à água por decorrer do regime democrático e dos princípios constitucionais, a partir da clausula de abertura constitucional, foi utilizado o método dedutivo e a pesquisa bibliográfica acerca da teoria dos direitos fundamentais. A conclusão é de que o regime democrático e determinados princípios constitucionais fundamentam a caracterização do direito de acesso à água como direito fundamental.

PALAVRAS-CHAVE: Direito de acesso à água; Direitos Fundamentais; Cláusula de abertura constitucional; Regime democrático; Princípios constitucionais.

\section{THE FUNDAMENTAL RIGHT TO WATER FROM THE DEMOCRATIC REGIME AND THE CONSTITUTIONAL PRINCIPLES}

\begin{abstract}
:
This paper analyzes the recognition of the fundamental right to access water based on the democratic regime adopted by the Brazilian State and the constitutional principles. In order to face the proposed problem, on the possibility of recognizing as fundamental the right of access to water due to the democratic regime and constitutional principles, from the constitutional opening clause, the deductive method and bibliographical research on the theory of fundamental rights. The conclusion is that the democratic regime and certain constitutional principles ground the characterization of the right of access to water as a fundamental right.
\end{abstract}

KEY WORDS: Right of access to water; Fundamental rights; Constitutional opening clause; Democratic regime; Constitutional principles.

\section{INTRODUÇÃO}

O reconhecimento do direito de acesso à água como um direito fundamental que decorre do regime democrático e dos princípios constitucionais é o objeto analisado neste trabalho.

\footnotetext{
${ }^{1}$ Pós-Doutorando PPGD/UFSC, Doutor em Direito pela Faculdade de Direito da Universidade de Lisboa, Mestre/UFSM e Professor Curso de Direito/UFN. joaohelio@ufn.edu.br
} 
Os fundamentos da definição do direito de acesso à água como direito fundamental podem ser os mais variados. Entre as várias possibilidades, a clausula de abertura constitucional, prevista no artigo $5^{\circ}, \S 2^{\circ}$, da Constituição brasileira, reconhece a fundamentalidade dos direitos como decorrência dos princípios constitucionais; do regime democrático adotado pelo Estado brasileiro; das normas de direitos humanos constantes em tratados do qual o Brasil seja parte e em decorrência do conteúdo de outros direitos fundamentais. A análise da caracterização do direito de acesso à água como direito fundamental é delimitada, neste trabalho, de forma proposital, a alternativa decorrente do regime democrático e dos princípios constitucionais adotados pelo Estado brasileiro, portanto, não sendo abordadas as demais possibilidades.

Assim, o problema de pesquisa pode ser sintetizado da seguinte forma: é possível reconhecer como fundamental o direito de acesso à água, por meio da clausula de abertura constitucional, em decorrência do regime democrático e dos princípios constitucionais adotados pelo Estado brasileiro?

Para desenvolver o tema e apresentar uma resposta, minimamente adequada, foi utilizado o método dedutivo a partir de elementos da Teoria dos Direitos Fundamentais e de consulta bibliográfica à produção doutrinaria reconhecida academicamente.

$\mathrm{O}$ artigo está dividido em duas partes, sendo que a primeira analisa a clausula de abertura constitucional para o reconhecimento de novos direitos fundamentais, notadamente do direito de acesso à água. A segunda parte trata da fundamentalidade do direito de acesso à água que decorre do regime democrático e dos princípios constitucionais, com base da teoria dos direitos fundamentais.

A conclusão é de que o regime democrático e alguns princípios adotados pela Constituição brasileira fundamentam a caracterização do direito de acesso à água como direito fundamental.

\section{A ABERTURA DA CONSTITUIÇÃO PARA O RECONHECIMENTO DO DIREITO FUNDAMENTAL DE ACESSO À ÁGUA}

O direito de acesso à água potável não se encontra expressamente disposto no texto Constitucional da República Federativa do Brasil, portanto, faz-se necessário analisar os fundamentos utilizados para reconhecer o acesso à água como um direito fundamental. 
Assim, para caracterizar o acesso à água como um direito fundamental é preciso verificar, por meio de um processo metodológico dedutivo simples, se esse direito, com todas as suas peculiaridades, corresponde ao que foi definido como direito fundamental. Além disso, por meio de um processo metodológico mais complexo, é necessário justificar a fundamentalidade do direito de acesso à água potável (PES, 2019, p.84).

No Estado brasileiro, o direito de acesso à água potável, por não ser norma expressa no texto constitucional (fundamentalidade formal), é tratada como norma que deve ser (fundamentalidade material).

Nesse sentido, é imprescindível verificar à luz do ordenamento jurídico brasileiro 'a fundamentalidade dos direitos a partir da cláusula de abertura constitucional'. A 'cláusula aberta' dos direitos fundamentais, também denominada de 'cláusula de abertura constitucional', nos termos da atual Constituição Brasileira, admite considerar como direitos fundamentais determinadas situações jurídicas não previstas na Constituição (chamados de direitos fundamentais não expressos, não escritos ou não enumerados). Assim, com a adoção da "cláusula aberta ou de não tipicidade dos direitos fundamentais" (MIRANDA, 2000, p. 162), passam a ser também considerados direitos fundamentais aqueles que decorrem do regime democrático, dos outros princípios adotados pela Constituição Brasileira e dos tratados de direitos humanos.

Nesse viés, a Constituição Brasileira aceita outros direitos além daqueles nela expressamente previstos. "Esses direitos não são aqueles que as normas formalmente constitucionais enunciam e, sim, aqueles que são ou podem ser também direitos provenientes de outras fontes, na perspectiva mais ampla da Constituição material” (CUNHA JÚNIOR, 2013, p. 617).

$\mathrm{O} \S 2^{\circ}$ do artigo $5^{\circ}$ da Constituição Federal, assim expresso: "Os direitos e garantias expressos nesta Constituição não excluem outros decorrentes do regime e dos princípios por ela adotados, ou dos tratados internacionais em que a República Federativa do Brasil seja parte;" (BRASIL. Constituição Brasileira de 1988), deixa claro que a enumeração dos direitos fundamentais é aberta e, por ser meramente exemplificativa, pode ser complementada a qualquer momento por outros direitos, por meio de outras fontes.

A origem dessa cláusula, incluída desde a primeira Constituição Republicana brasileira de 1891, tem como referencial histórico a Constituição dos Estados Unidos da América que, ao receber o aditamento IX ( $9^{\text {a }}$ Emenda Constitucional) em 1791, fixou a 
seguinte regra: "enumeração de certos direitos na Constituição não deve ser interpretada como denegação ou diminuição de outros direitos reservados ao povo" (PES, 2010, 50).

Portanto, as normas de direitos fundamentais não se restringem aos dispositivos constitucionais previstos no capítulo próprio. No direito brasileiro, elas se apresentam de diferentes formas, seja como enunciados de emendas constitucionais ou de tratados de direitos humanos, ou ainda, de forma não escrita, como normas implícitas, decorrentes de outros dispositivos constitucionais, do regime democrático adotado e dos princípios constitucionais.

Assim, sem destoar drasticamente das classificações de José Afonso da Silva (2004, p. 193), Ingo Sarlet (2010, p. 161) e de Flávia Piovesan (2008, p. 58), classificam-se as normas de direitos fundamentais, previstas ou reconhecidas pela Constituição brasileira, em quatro grupos: 1) Expressas ou escritas na Constituição: (a) no catálogo dos direitos fundamentais; (b) fora do catálogo e dispersas no texto constitucional; 2) Expressas ou escritas fora da Constituição: (a) nas Emendas Constitucionais; (b)nos tratados de Direitos Humanos internalizados pelo Art. $5^{\circ}, \S 3^{\circ} ; 3$ ) implícitas: (a) implícitas no sentido estrito ou, implícitas propriamente ditas, que resultam de uma dedução das normas fundamentais expressas na Constituição; (b) implícitas decorrentes do regime democrático e dos princípios constitucionais; 4) expressas ou implícitas nos tratados de direitos humanos internalizados de acordo com Art. $5^{\circ}, \S 2^{\circ}$.

Tal classificação é adotada no sentido de facilitar a identificação de quais normas são 'formal e materialmente fundamentais' (grupos 1 e 2) e quais são 'só materialmente fundamentais' (grupos 3 e 4). Além disso, são facilmente identificadas como normas que têm a fundamentalidade reconhecida a partir da cláusula de abertura constitucional aquelas classificadas nos grupos 3 e 4 .

Assim, são normas formalmente fundamentais, ou direitos fundamentais constitucionalizados formalmente, aquelas positivadas ou incorporadas na ordem jurídica positiva, seja no catálogo desses direitos (parte da Constituição em que se enumeram os direitos fundamentais), seja fora do catálogo (direitos dispersos no próprio texto) ou fora do texto, como as Emendas Constitucionais brasileiras (a exemplo do direito de aposentadoria integral, previsto no art. $3^{\circ}$ da Emenda Constitucional no 47 de 05 de julho de 2005) e, ainda, os direitos humanos provenientes de tratados internacionais internalizados pelo procedimento do Art. $5^{\circ}, \S 3^{\circ}$ da Constituição. Outrossim, são normas materialmente fundamentais, ou direitos reconhecidos pela Constituição como fundamentais, aquelas que resultam de uma 
dedução das normas fundamentais expressas na Constituição, aqueles que decorrem do regime democrático e dos princípios constitucionais e aquelas que constam nos tratados de direitos humanos internalizados de acordo com Art. $5^{\circ}, \S 2^{\circ}$.

O reconhecimento de um determinado direito como fundamental a partir da cláusula de abertura constitucional pode ser denominado de processo de constitucionalização material de direitos fundamentais. Esse processo consiste em considerar direitos (de acordo com o significado e conteúdo) como autênticos direitos fundamentais, sem, necessariamente, estarem expressos no texto da Carta Magna; implica terem esses direitos um tratamento jurídico de acordo com o prescrito, em geral, para todos os direitos fundamentais.

Assim, tanto os direitos fundamentais expressos ou escritos (na própria Constituição, nas Emendas ou nos tratados de direitos humanos internalizados pelo procedimento específico) como aqueles não expressos ou implícitos, direitos com valor de norma constitucional, têm um regime jurídico especial, com os seguintes efeitos (decorrentes desse processo de constitucionalização): 1) são protegidos pela constituição como normas supremas, portanto, prevalecem sobre as normas infraconstitucionais; 2) não podem ser abolidos (materialmente) por emenda constitucional, seus conteúdos não podem ser objeto de emendas tendentes à redução ou eliminação de direitos (direitos exercidos pelo individuo); 3) vinculam imediatamente os poderes públicos (legislativo, judiciário e executivo) e, na maior medida possível, os particulares e 4) desfrutam, também, na maior medida possível, de aplicabilidade imediata.

Portanto, os direitos materialmente constitucionais gozam de idêntica hierarquia e prestígio que os formalmente constitucionais, assim, quando em conflito com outros direitos fundamentais, resolve-se o caso pela mesma forma tradicional de solução de conflitos. Ressalta-se, porém, que, tratando-se de Direitos Humanos, aplica-se o princípio da norma mais favorável à pessoa.

O processo de constitucionalização material, tendo por base a cláusula aberta prevista na Constituição brasileira no art. $5^{\circ}, \S 2^{\circ}$, admite a fundamentalização daqueles direitos não previstos expressamente por ela, mas que, por força de sua essencialidade, ou seja, de conteúdo e importância, são direitos fundamentais equivalentes aos direitos formalmente constitucionalizados (PES, 2019, P. 91). Inegavelmente, o reconhecimento de novos direitos como fundamentais a partir da cláusula de abertura constitucional, na 
classificação de direitos fundamentais implícitos propriamente ditos, somente ocorre após uma correta justificação da fundamentalidade de cada um desses novos direitos.

O direito de acesso à água potável, para ser identificado como um direito fundamental derivado do conteúdo de outros direitos fundamentais necessita de uma justificação plausível. Esse processo de justificação se dá, juridicamente, por meio do reconhecimento de um direito fundamental implícito em sentido estrito.

Os Direitos fundamentais implícitos em sentido estrito são aqueles definidos como direitos outorgados por normas que podem ser deduzidas daquelas normas diretamente estatuídas no rol dos direitos fundamentais ou em outras partes do texto constitucional.

A Constituição Brasileira estabelece no Título II (Artigo $5^{\circ}$ ao 17) os direitos e garantias fundamentais, no qual estão contidas, dentre outras, as cláusulas gerais da liberdade e da igualdade, imprescindíveis, na concepção de Dworkin (1999), para a constituição de uma sociedade de livres e iguais. Estabelece, também, no Título I (Artigo $1^{\circ}$ ao $4^{\circ}$ ) os princípios fundamentais do Estado brasileiro, neles constando, dentre outros, os princípios da cidadania; da dignidade da pessoa humana; do pluralismo político; da soberania popular; o ideal político de uma sociedade livre, justa e solidária; de erradicação da pobreza e da marginalização; de promoção do bem de todos, sem quaisquer preconceitos; de prevalência dos direitos humanos e de cooperação entre os povos para o progresso da humanidade. Esse conjunto de princípios e regras é que possibilita uma interpretação construtiva que resulta na identificação de direitos fundamentais implícitos.

O reconhecimento de um direito como fundamental, quando não há norma constitucional expressa, requer o estabelecimento prévio dos critérios dessa fundamentalidade. Em outras palavras, é necessário estabelecer quais características materiais constituem o citado direito e a sua conformidade com o ordenamento jurídico estabelecido para que a definição do que representa a fundamentalidade não fique apenas ao arbítrio do intérprete.

O constituinte brasileiro, ao elaborar uma extensa e detalhada lista de direitos fundamentais, prevista no capítulo próprio ou esparsa no texto constitucional, objetivou concretizar as prerrogativas inerentes à liberdade e à igualdade. Todos esses direitos, outorgados por normas expressas, têm como finalidade última efetivar o respeito à dignidade humana. Nada impede que se reconheça a existência de direitos implícitos decorrentes de normas expressas, que tenham também como finalidade a observância da mesma dignidade, 
imprescindível para constituir uma sociedade solidária na qual prepondere a liberdade e a igualdade.

Para Ronald Dworkin (1999, p. 202) os direitos implícitos se encontram entre os direitos explícitos, identificáveis pela interpretação construtiva da prática jurídica, em que o Estado deve agir segundo um conjunto único e coerente de princípios. Essa interpretação é própria da "teoria do direito como integridade", na qual o ideal político da integridade se agrega aos princípios de justiça, equidade e devido processo, para a consolidação de uma sociedade de livres e iguais.

Assim, o direito de acesso à água potável como um direito fundamental implícito, deduzido de uma norma diretamente estatuída no texto constitucional, pode ser encontrado no conteúdo de outros direitos fundamentais, como no direito ao ambiente, previsto no artigo 225 , ou no direito à vida estatuído no artigo $5^{\circ}$, ou ainda, em outros direitos sociais como o direito à saúde, o direito à moradia e à alimentação, dentre outros, previstos no artigo $6^{\circ}$ da Constituição brasileira.

\section{A FUNDAMENTALIDADE DO DIREITO DE ACESSO À ÁGUA QUE DECORRE DO REGIME DEMOCRÁTICO E DOS PRINCÍPIOS CONSTITUCIONAIS}

O direito de acesso à água potável, para ser identificado como um direito fundamental decorrente do regime democrático e dos princípios adotados pela Constituição Brasileira, necessita, também, de uma fundamentação correta de sua existência. Uma norma implícita de direito fundamental é plenamente justificada quando se demonstra que ela é uma exigência do próprio sistema de direitos fundamentais.

Portanto, os direitos decorrentes do regime e dos princípios fundamentais podem ser entendidos como os direitos diretamente justificados a partir da estrutura normativa mais geral do sistema de direitos (PES, 2019, p. 125). O sistema de direitos fundamentais e o regime democrático vigentes no Estado Brasileiro estão consubstanciados no significado das expressões 'Estado Democrático' e 'Estado Democrático de Direito', incluídas, respectivamente, no preâmbulo e no artigo $1^{\circ}$ da Constituição Federal (BRASIL. Constituição Brasileira de 1988). 
O Estado Democrático de Direito se diferencia do Estado Liberal de Direito e do Estado Social de Direito. O Estado Liberal considera o 'direito' como um sistema normativo de regras gerais, abstratas e negativas, com o Estado limitado à legalidade, garantidos os direitos individuais típicos e, consequentemente, preponderando uma ordem jurídica liberal clássica. O Estado Social de Direito tem o direito como instrumento de ação concreta do Estado para materializar as pretensões sociais transformadas em direitos formais, com a ampliação das tarefas estatais no âmbito social e econômico (STRECK; MORAIS, 2001, p. 92-99). Frente às crises desses modelos de estados, surge o modelo de Estado Democrático de Direito sustentado na ideia de um direito participativo, pluralista e aberto. "A consideração de que o ordenamento jurídico é composto por princípios, além de regras, é também uma exigência do paradigma constitucional do Estado Democrático de Direito" (PARDO, 2005, p. 273).

A teoria do discurso também sustenta a tese de que a melhor leitura do regime constitucional democrático é aquela fornecida por uma teoria constitucional baseada nos direitos. É nesse contexto que essa teoria assume explicitamente que a ideia do discurso só pode se realizar no modelo de Estado Constitucional Democrático (ALEXY, 1995, p. 129131). Convém observar que, na vigência do Estado Democrático de Direito, surge de forma mais intensa a interpretação de que há direitos fundamentais implícitos que decorrem das posições jurídicas justificadas a partir dos princípios da Constituição e de acordo com a melhor leitura do regime democrático. Assim, "O Estado Democrático de Direito é antes de tudo uma forma paradigmática de interpretar a ordem constitucional e, desse modo, também o sistema de direitos fundamentais" (PARDO, 2005, p. 272).

Nesse sentido, doutrinariamente ${ }^{2}$ o sistema de direitos fundamentais tem sido concebido como um sistema de normas que abarcam tanto regras quanto princípios. A distinção entre princípios e regras é um assunto complexo, não há dúvida de que a grande discussão sobre esse problema ganhou a força atual com as obras de Ronald Dworkin e Robert Alexy.

\footnotetext{
${ }^{2}$ Autores que expressam tal compreensão: DWORKIN, Ronald. Levando os direitos a sério. São Paulo, SP: Martins Fontes, 2002; ALEXY, Robert. Teoria dos Direitos Fundamentais. Trad. Virgilio Afonso da Silva. São Paulo: Melhoramentos, 2008; e SILVA, Virgilio Afonso da. Direitos Fundamentais - conteúdo essencial, restrições e eficácia. $2^{\mathrm{a}}$ edição. São Paulo Melhoramentos, 2010. Com ressalvas discordantes: HART, Herbert L. A.. O conceito de direito. $5^{\mathrm{a}}$ ed..Lisboa: Fundação Caloute Gulbenkian, 2007, p. 321).
} 
Nesse contexto, as regras devem ser assimiladas como disciplinadoras de determinada situação, são a expressão literal de um fato que pode ou não ocorrer, e, caso ocorra, essa norma que o define incidirá sobre o mesmo. Por outro lado, os princípios "normalmente apontam para estados ideais a serem buscados, sem que a norma descreva de maneira objetiva a conduta a ser seguida" (BARROSO, 2009, p 206).

Para Alexy, os princípios são normas que ordenam que algo seja realizado na maior medida possível dentro das possibilidades jurídicas e fáticas existentes, sendo verdadeiros mandamentos de otimização. Fazendo uma distinção qualitativa e não uma distinção de grau, Alexy define as regras como normas que são sempre satisfeitas ou não satisfeitas, enfatizando que se uma regra vale, então, deve se fazer exatamente aquilo que ela exige; nem mais, nem menos. Conclui que regras contêm determinações no âmbito daquilo que é fática e juridicamente possível (ALEXY, 2008, p. 90-91).

David Wilson de Abreu Pardo, mencionando as lições de Ronald Dworkin afirma que o sistema de direitos configura um sistema compreensivo, em que os preceitos da igual consideração e das liberdades básicas se tornam os maiores fundamentos, as maiores fontes dos direitos individuais. Na medida em que o conjunto de princípios básicos tem um conteúdo normativo aberto, outros direitos particulares podem surgir de dito esquema. "Sendo assim, direitos fundamentais também podem ser encontrados de maneira imediata a partir das referidas cláusulas abstratas de acentuado teor moral, sem necessariamente terem de estar desde o início detalhados em uma constituição" (PARDO, 2005, p. 269).

É nesse sentido que os princípios gerais da dignidade, da liberdade e da igualdade emergem como a base normativa mais abstrata dos direitos humanos fundamentais. Luis Prieto Sanchís, de forma magistral, referindo-se à relação histórica entre direitos humanos, liberdade, igualdade e dignidade chegou a afirmar que "somente estaremos na presença de um direito fundamental quando se possa razoavelmente sustentar que o direito ou instituição serve a algum desses valores" (SANCHÍS, 1990, p. 88).

Nesse sentido, a existência de princípios que norteiam a Constituição Federal brasileira, como são os princípios da dignidade da pessoa humana, da liberdade e da igualdade, dentre outros, garante fundamentos racionais para se considerar o acesso à água potável um direito materialmente fundamental no ordenamento jurídico brasileiro. 
Jorge Miranda afirma que devem ser considerados direitos materialmente fundamentais apenas aqueles que, "pela sua finalidade ou pela sua fundamentalidade, pela conjugação com direitos fundamentais formais, pela natureza análoga à desses, ou pela sua decorrência imediata de princípios constitucionais, se situem a nível da Constituição material” (MIRANDA, 2001, p. 568). Nesse sentido, entendo que o direito de acesso à água potável pode ser considerado norma de direito materialmente fundamental por ser uma norma que decorre das normas relativas ao regime e aos princípios da Constituição.

Na Constituição Brasileira é possível identificar cláusulas gerais que expressam os princípios da liberdade e da igualdade, contidas no próprio Título II, mais precisamente no caput do Artigo $5^{\circ}$. Já o princípio da dignidade da pessoa humana está localizado entre os princípios fundamentais estabelecidos no Título I, artigo $1^{\circ}$, inciso III (BRASIL. Constituição Brasileira de 1988). Portanto, ao analisar quais são os direitos que decorrem do regime e dos princípios, é necessário mencionar aqueles que podem ser justificados a partir da estrutura normativa básica delineada pelos princípios da liberdade, da igualdade e da dignidade humana.

Não há como deixar de reconhecer que é na dignidade da pessoa humana que reside o fundamento principal, a base sólida e concreta de um conceito material dos direitos fundamentais. Por isso, quanto ao direito de acesso à água potável, a fundamentação substancial desse direito está estritamente ligada à dignidade que deve ser reconhecida em cada ser humano. Como admitir o reconhecimento do respeito à dignidade de um ser humano que com sede não tem água; ou com fome não tem acesso à água de qualidade para preparar seus alimentos; ou, ainda, com as roupas sujas lhes falta água limpa para lavá-las?

O reconhecimento de determinados direitos como fundamentais, não expressos ou não escritos no texto constitucional, podem decorrer do princípio da dignidade da pessoa humana. O reconhecimento do direito à moradia e do direito à alimentação como fundamentais era efetuado por decorrência do princípio da dignidade da pessoa humana. Isso ocorria antes da inclusão desses direitos no rol dos direitos fundamentais sociais, respectivamente pelas Emendas Constitucionais $n^{\circ}$ 26/2000 e 64/2010. Além da jurisprudência do Superior Tribunal de Justiça, anteriormente referida (BRASIL. Superior Tribunal de Justiça, 1999), há uma famosa jurisprudência francesa referida por Ingo Sarlet (2002, p. 137-193): trata-se da Decisão no 94-359, de 19.01.95, do Conselho Constitucional 
Francês na qual se reconhece a possibilidade de toda pessoa dispor de um alojamento decente, tendo como fundamento o princípio da dignidade da pessoa humana, independente da previsão expressa na ordem constitucional.

É preciso concordar com José Carlos Vieira de Andrade quando afirma que é o princípio da dignidade da pessoa humana que confere unidade de sentido ao conjunto dos preceitos relativos aos direitos fundamentais: "Realmente, o princípio da dignidade da pessoa humana (individual) está na base de todos os direitos constitucionalmente consagrados" (ANDRADE, 2004, p. 102).

Os direitos a prestações sociais estão intimamente vinculados ao direito à vida e ao princípio da dignidade da pessoa humana. A possibilidade de se exigir compulsoriamente as prestações asseguradas no ordenamento jurídico tem como fundamento último o respeito à dignidade inerente a cada um (PES, 2019, p. 128).

Vale lembrar que, na concretização do princípio da dignidade, pressupõe-se vida digna e saudável, no mesmo sentido da expressão constitucional prevista no artigo 225 de promoção da "sadia qualidade de vida". Nesse sentido, Ingo Sarlet e Tiago Fenterseifer (2012, p. 120) afirmam que a dignidade da pessoa humana "somente estará assegurada - em termos de condições básicas a serem garantidas pelo Estado e pela sociedade - onde a todos e a qualquer um estiver assegurada nem mais nem menos do que uma vida saudável”. Convém lembrar, também, que a promoção de uma sadia qualidade de vida somente é possível se o acesso à água potável for um direito a todos e a cada um assegurados.

Portanto, o reconhecimento do direito de acesso à água potável como um direito fundamental, em decorrência do princípio da dignidade da pessoa humana, positivado na Constituição Brasileira no art. $1^{\circ}$, inciso III, está estreitamente relacionado à dimensão ou perspectiva positiva desse princípio constitucional, que contempla no seu conteúdo a satisfação das necessidades existenciais básicas para uma vida com dignidade, próprias do mínimo existencial.

Várias são as implicações da inclusão do princípio da dignidade da pessoa humana como um dos pilares da Constituição Federal brasileira. Uma dessas implicações é a necessidade de discriminar o que deve ser considerado como imprescindível para viver com dignidade. Porém, é necessário fazê-lo levando em consideração o panorama atual de nossa sociedade. Ou seja, a definição do que se constitui em mínimo existencial deve ser balizada 
dentro das demandas sociais contemporâneas, considerando que a constante evolução tecnológica e social requer uma permanente atualização das demandas sociais para uma vida digna.

O princípio da dignidade da pessoa humana foi o fundamento principal da transformação do Estado de Direito para o Estado Social de Direito. Essa evolução do Estado também é permanente, sendo que hoje o Estado constitucional contemporâneo projeta uma medida de proteção ambiental mínima, tendo como fundamento, também, a dignidade humana (HÄBERLE, 2005, p. 130).

Nesse aspecto, é necessário reconhecer que passa a ser dever do Estado garantir as prestações materiais mínimas daquilo que se compreende como mínimo existencial social, cultural e ambiental. Essas prestações são necessárias ao bem-estar e à dignidade das pessoas, principalmente daquelas em situação de vulnerabilidade social e econômica, mesmo que as dificuldades sejam transitórias, como nas situações de impossibilidade de efetuar o pagamento das tarifas dos serviços de abastecimento de água potável.

Nesse sentido, dizem respeito ao mínimo existencial, além daqueles direitos fundamentais já expressos no texto constitucional, "o direito ao fornecimento de serviços existenciais básicos, como água, saneamento básico, transporte, energia elétrica (ainda que possam ser reportados a outros direitos fundamentais) (SARLET, 2010, p.322)”. Portanto, integram o conteúdo do mínimo existencial direitos fundamentais expressos e implícitos. $\mathrm{O}$ próprio direito a um mínimo existencial, na condição de direito fundamental, é um direito implícito decorrente do princípio da dignidade da pessoa humana.

A configuração do direito fundamental a um mínimo existencial ambiental comporta uma série de condições materiais imprescindíveis para uma existência digna. Destaca-se a qualidade ambiental diante do quadro, infelizmente real, de degradação da natureza, de péssimas condições de moradia, de centros urbanos localizados em área de risco, rios e córregos totalmente poluídos, etc.; "tais condições materiais elementares constituem-se de premissas ao próprio exercício dos demais direitos (fundamentais ou não), resultando, em razão da sua essencialidade ao quadro existencial humano, em um direito a ter e exercer os demais direitos" (FENSTERSEIFER, 2009, p. 286). Sem a garantia do mínimo existencial ambiental, com a definição de um padrão mínimo de qualidade ambiental, os demais direitos 
fundamentais dificilmente serão exercidos na sua plenitude e, além disso, não é possível pensar em uma existência compatível com a promoção e o respeito à dignidade humana.

Assim, a fundamentação do mínimo existencial ambiental ou ecológico, para Thiago Fensterseifer, é alcançada com a ampliação do conceito de mínimo existencial “a fim de abarcar a ideia de uma vida com qualidade ambiental (e, por óbvio, com dignidade), em que pese a sobrevivência humana (e, portanto, o mínimo vital) também se encontrar muitas vezes ameaçada pela degradação ambiental" (FENSTERSEIFER, 2009, p. 287).

Inegavelmente, o mínimo existencial deve ser compreendido de forma ampliada com o objetivo de incluir a qualidade ambiental dentre os fatores considerados imprescindíveis para a efetividade do princípio da dignidade da pessoa humana. Não há dúvidas de que o acesso à água potável é um desses fatores, que, por sua vez, também está estreitamente vinculado ao mínimo existencial ambiental.

O mínimo existencial na condição de direito-garantia vinculado ao direito de acesso à água potável não pode ser reduzido a um objeto previamente fixado, muito menos a uma quantidade genericamente determinada de água, no sentido de uma quantidade préestabelecida como ideal. Isso porque a definição do que integra o mínimo existencial depende de fatores relacionados às condições pessoais do titular do direito, além daqueles de ordem social, cultural e econômica.

Por outro lado, mesmo que o direito de acesso à água potável quando vinculado ao mínimo existencial possa ser compreendido como um direito subjetivo definitivo, passível de ser exigível por se tratar de um dever de prestações para o destinatário da norma fundamental, isso não significa que ele possa ser caracterizado como um direito absoluto, eis que pode ser relativizado no processo de aplicação, assim como os demais direitos fundamentais.

É preciso frisar, ainda, que o direito fundamental de acesso à água potável no processo de aplicação ao caso concreto pode receber o reforço do Princípio da Prevalência dos Direitos Humanos. A Prevalência dos Direitos Humanos está arrolada como um dos princípios fundamentais do Estado, no título I, da Constituição brasileira, no seu artigo $4^{\circ}$. Mesmo estando localizado no artigo que trata das relações internacionais, ele tem como função reger o Estado brasileiro nas relações internas e externas (BRASIL. Constituição Brasileira de 1988). 
Ao analisar o Princípio da Prevalência dos Direitos Humanos como princípio fundamental a reger o Estado brasileiro nas relações internacionais, Celso Lafer (LAFER, 2005. p. 14) explica que está presente "no art. 4. ${ }^{\circ}$, clara nota identificadora da passagem do regime autoritário para o Estado Democrático de Direito". Assevera, ainda, que "este princípio afirma uma visão do mundo - que permeia a Constituição de 1988 - na qual o exercício do poder não pode se limitar à perspectiva dos governantes, mas deve incorporar a perspectiva de cidadania" (LAFER, 2005. p. 14).

Flavia Piovesan enfatiza que "cabe ainda considerar que o princípio da prevalência dos direitos humanos contribuiu substantivamente para o sucesso da ratificação, pelo Estado brasileiro, de instrumentos internacionais de proteção dos direitos humanos" (PIOVESAN, 2008, p. 41), inclusive do Pacto dos Direitos Econômicos, Sociais e Culturais e de outros tratados internacionais que internalizaram direitos humanos com conteúdo relacionado ao direito de acesso à água potável.

A fundamentalidade do direito de acesso à água potável, além de decorrer do princípio da dignidade humana, decorre também do regime democrático e do princípio da igualdade. O princípio da igualdade está previsto no artigo $5^{\circ}$, caput, da Constituição Brasileira, na medida em que garante um direito geral de igualdade. $O$ direito geral de igualdade compreende o mandamento da igualdade na aplicação do direito e o mandamento da igualdade na criação do direito (ALEXY, 2008, p. 393).

$\mathrm{Na}$ criação ou formulação do direito, é preciso levar em conta o ensinamento de Robert Alexy (2008, p. 397), amparado nas lições de Aristóteles, de que se deve ter, sempre, presente a formula clássica de tratar igual ao igual e desigual ao desigual, o que resulta no mandamento de que estão proibidos os tratamentos arbitrariamente desiguais. Nesse sentido, é vedado ao legislador criar normas reguladoras do direito de acesso à água potável que possam restringir o direito de acesso em algumas situações e que caracterizem tratamento desigual, inclusive por razões econômicas.

$\mathrm{Na}$ aplicação, o direito geral de igualdade, ao prever que "Todos são iguais perante a lei" e que não pode ser violado o direito à igualdade, deve ser interpretado no sentido de considerar o termo 'lei' com o significado de 'direito', ou seja, todos devem ser tratados com igualdade, considerando o conjunto de normas (princípios e regras) do sistema jurídico e os valores jurídicos e sociais próprios do Estado Democrático de Direito. 
Lênio Streck e José Luís Bolzan de Morais, ao abordarem a evolução do modelo de Estado Democrático de Direito em relação aos modelos anteriores, afirmam que ocorreu: “com este novo modelo a incorporação efetiva da questão da igualdade como um conteúdo próprio a ser buscado garantir através do asseguramento jurídico de condições mínimas de vida ao cidadão e à comunidade" (STRECK; MORAIS, 2001, p. 97). Assim, verifica-se que o princípio da igualdade é também uma exigência do regime de estado adotado pela Constituição Brasileira.

Por outro lado, esse princípio está estreitamente relacionado aos direitos sociais que, ao serem efetivados, cumprem com a finalidade última da diretriz de igualdade. Na relação com o direito social de acesso à água potável, o princípio da igualdade cumpre a finalidade de assegurar as condições mínimas de vida aos titulares desse direito.

Luis Prieto Sanchís (1990, p. 88) afirma que é possível tratar como direito fundamental aquele direito que se possa razoavelmente sustentar que, em sua aplicação serve à dignidade humana, ou à liberdade, ou à igualdade. Nessa vereda, o direito fundamental de acesso à água potável pode ser sustentado como um direito que está estreitamente relacionado ao princípio da igualdade; o exercício desse direito proporciona não só a satisfação de uma necessidade humana, mas também a afirmação da importância do tratamento igualitário.

Assim, vale ratificar que o direito de acesso à água pode ser reconhecido como um direito fundamental implícito, em sentido amplo, decorrente do regime democrático e dos princípios adotados pela Constituição. A justificação desse reconhecimento deriva de uma interpretação do Estado Democrático de Direito e dos princípios constitucionais formalmente expressos ou consensualmente reconhecidos, como os princípios da igualdade e da dignidade humana, dentre outros (PES, 2019, p. 133).

Concretamente, o direito de acesso à água, reconhecido como direito fundamental a partir da estrutura normativa básica do Estado Democrático de Direito, do sistema de direitos fundamentais, do regime democrático e dos princípios constitucionais, do princípio da dignidade da pessoa humana, do mínimo existencial e do princípio da igualdade, especificamente pela previsão normativa do direito geral de igualdade, justifica-se como realmente fundamental pela relação com a finalidade de proteção à dignidade das pessoas.

\section{CONCLUSÃO}

Revista Brasileira de Filosofia do Direito | e-ISSN: 2526-012X | Belém | v. 5 | n. 2 | p. 01 - 20 | Jul/Dez. 2019. 
O reconhecimento de um direito como materialmente fundamental ocorre por meio da 'cláusula de abertura constitucional', nos termos artigo $5^{\circ}, \S 2^{\circ}$, da atual Constituição Brasileira. Essa cláusula deixa claro que a enumeração dos direitos fundamentais é aberta, meramente exemplificativa, podendo ser complementada a qualquer momento por outros direitos, por meio de outras fontes. Assim, são direitos fundamentais determinadas situações jurídicas não previstas na Constituição, ou seja, são considerados direitos fundamentais outros direitos além daqueles nela expressamente previstos. Portanto, pela nossa cláusula aberta, podem ser também considerados direitos fundamentais aqueles que decorrem do conteúdo de outros direitos fundamentais expressos no texto constitucional, do regime democrático, dos outros princípios adotados pela Constituição Brasileira e dos tratados de direitos humanos.

A análise da caracterização do direito de acesso à água como direito fundamental foi delimitada a uma das alternativas possíveis, ou seja, o reconhecimento da fundamentalidade do direito de acesso à água por decorrência do regime democrático e dos princípios constitucionais adotados pelo Estado brasileiro, sem abordar, nesse trabalho, as demais possibilidades.

O direito de acesso à água potável pode ser reconhecido como um direito fundamental implícito, em sentido amplo, por decorrência do regime democrático e dos princípios adotados pela Constituição Brasileira. Os direitos decorrentes do regime e dos princípios constitucionais podem ser entendidos como direitos fundamentais, plenamente justificados, a partir da demonstração de que eles são uma exigência do próprio sistema de direitos fundamentais. Nesse sentido, o direito de acesso à água potável pode ser identificado como um direito materialmente fundamental a partir da estrutura normativa básica do Estado Democrático de Direito, especialmente do regime democrático adotado e dos princípios constitucionais, como o da dignidade da pessoa humana, da liberdade e da igualdade.

Assim, a conclusão de que são várias as formas de reconhecimento do direito de acesso à água potável como um direito fundamental reforça a tese de que o dever de fornecimento de água potável nos serviços públicos de abastecimento, além de ser uma tarefa do Estado, é um dever conexo ou correlato ao direito fundamental de acesso à água potável.

Portanto, para responder a problemática, inicialmente proposta, sobre a possibilidade de reconhecer como fundamental o direito de acesso à água, por decorrer do regime 
democrático e dos princípios constitucionais, a partir da clausula de abertura constitucional, a conclusão é de que o regime democrático e determinados princípios constitucionais fundamentam a caracterização do direito de acesso à água como direito fundamental.

\section{REFERÊNCIAS}

ALBUQUERQUE, Catarina de. Derechos hacia el final: buenas prácticas en la realización de los derechos al agua i al saneamiento. Madrid: ONGAWA, Ingeniería para el Desarrollo Humano, 2011.

ANDRADE, José Carlos Vieira de. Os direitos fundamentais na Constituição Portuguesa de 1976. Coimbra: Livraria Almedina, $3^{\text {a }}$ Ed., 2004.

BRASIL. Constituição brasileira de 1988. Disponível em http://www.planalto.gov.br/ccivil_03/constituicao/constituicao.htm. Acesso em 04 ago. 2019.

BRASIL. Decreto n ${ }^{\circ}$ 7.752, de 14 de junho de 2012. Promulga a Constituição da Organização das Nações Unidas para a Alimentação e a Agricultura - FAO, firmada em Quebec, Canadá, em 16 de outubro de 1945. Disponível em http://www.planalto.gov.br/ccivil_03/_Ato20112014/2012/Decreto/D7752.htm. Acesso em 31 jul. 2019.

BRASIL. Decreto ${ }^{\circ} 7.217$, de 25 de agosto de 2009. Promulga a Convenção Internacional sobre os Direitos das Pessoas com Deficiência e seu Protocolo Facultativo, assinados em Nova York, em 30 de março de 2007. Disponível em http://www.planalto.gov.br/ccivil_03/_ato2007-2010/2009/decreto/d6949.htm. Acesso em 03 ago. 2019.

BRASIL. Decreto $n^{\circ} 4.377$ de 13 de setembro de 2002. Promulga a Convenção sobre a Eliminação de Todas as Formas de Discriminação contra a Mulher, de 1979. Disponível em http://www.planalto.gov.br/ccivil_03/decreto/2002/D4377.htm. Acesso em 03 ago. 2019.

BRASIL. Decreto $n^{\circ}$ 678, de 6 de novembro de 1992. Promulga a Convenção Americana sobre Direitos Humanos (Pacto de São José da Costa Rica), de 22 de novembro de 1969. Disponível em http://www.planalto.gov.br/ccivil_03/decreto/D0678.htm. Acesso em 05 ago. 2019.

BRASIL. Decreto no 592, de 6 de julho de 1992. Pacto Internacional sobre Direitos Civis e Políticos. Adotado pela Assembleia Geral das Nações Unidas, em 16 de dezembro de 1966, e ratificado pelo Brasil em 24 de janeiro de 1992, aprovado no Brasil pelo Decreto Legislativo $\mathrm{n}^{\mathrm{o}} 226$, de 12 de dezembro de 1991, e promulgado pelo decreto $\mathrm{n}^{\circ} 592$, de 6 de julho de 1992. Disponível em http://www.planalto.gov.br/ccivil_03/decreto/1990-1994/D0592.htm. Acesso em 31 jul. 2019.

BRASIL. Decreto $n^{\circ}$ 591, de 06 de julho de 1992. Pacto Internacional sobre Direitos Econômicos, Sociais e Culturais - PIDESC. Adotado pela Assembleia Geral das Nações 
Unidas, em 19 de dezembro de 1966, e ratificado pelo Brasil em 24 de janeiro de 1992, aprovado no Brasil pelo Decreto Legislativo $\mathrm{n}^{\circ} 226$, de 12 de dezembro de 1991, e promulgado pelo decreto $\mathrm{n}^{\circ}$ 591, de 6 de julho de 1992. Disponível em:

http://www.planalto.gov.br/ccivil_03/decreto/1990-1994/D0591.htm. Acesso em 31 jul. 2019.

BRASIL. Decreto ${ }^{\circ}$ 99.710, de 21 de novembro de 1990. Promulga a Convenção sobre os Direitos da Criança. Disponível em http://www.planalto.gov.br/ccivil_03/decreto/19901994/D99710.htm. Acesso em 04 ago. 2019.

BRASIL. Decreto-Lei no 986, de 21 de outubro de 1969. Institui normas básicas sobre alimentos. Disponível em http://www.planalto.gov.br/ccivil_03/decreto-lei/Del0986.htm. Acesso em 18 jul. 2019.

BRASIL. Lei 8.080 de 19 de setembro de 1990. Dispõe sobre as condições para a promoção, proteção e recuperação da saúde, a organização e o funcionamento dos serviços correspondentes e dá outras providências. Disponível em http://www.planalto.gov.br/ccivil_03/leis/18080.htm. Acesso em 28 jul 2019.

BRASIL. Supremo Tribunal Federal. HC n 87.585/TO. Rel. Min. Marco Aurelio. Brasil, nov. 2009. Disponível em

http://redir.stf.jus.br/paginadorpub/paginador.jsp?docTP=AC\&docID=597891. Acesso em 04 ago. 2019.

BRASIL. Supremo Tribunal Federal. Súmula Vinculante 25: É ilícita a prisão civil de depositário infiel, qualquer que seja a modalidade do depósito. Disponível em http://www.stf.jus.br. Acesso em 04 ago. 2019.

CALIL, Mário Lúcio Garcez. Efetividade dos direitos sociais: prestação jurisdicional com base na ponderação de princípios. Porto Alegre: Nuria Fabris, 2012.

COMPARATO, Fábio Konder. A Afirmação Histórica dos Direitos Humanos. VI edição. São Paulo: Saraiva, 2008.

EQUADOR, Constituição do Equador de 2008. Disponível em http://www.asambleanacional.gov.ec. Acesso em 04 ago. 2019.

FIGUEIREDO, Mariana Flichtiner. Direito fundamental à saúde: parâmetros para sua eficácia e efetividade. Porto Alegre: Livraria do. Advogado, 2007.

FILIPINAS. Constituição da República das Filipinas de 1987. Disponível em http://www.president.gov.ph. Acesso em 03 Ago. 2019.

GARCÍA, Aniza. El derecho humano al agua. Madrid: Editorial Trotta, 2008.

IRIGARAY, Carlos Teodoro José Hugueney. Água: um direito fundamental ou uma mercadoria? In: Congresso Internacional de Direito Ambiental, 2003, São Paulo. Direito Água e Vida. São Paulo: Imprensa Oficial, v. 1, p. 308-400, 2003. 
KRELL, Andreas J. Os direitos sociais e controle judicial no Brasil e na Alemanha. Os (des)caminhos de um direito constitucional "comparado". Porto Alegre: Sergio Antônio Fabris Editor, 2002.

LAFER, Celso. A Internacionalização dos Direitos Humanos: Constituição, Racismo e Relações Internacionais. São Paulo: Ed. Manole, 2005.

LOUREIRO, João Carlos. Direito à (proteção da) saúde. In Estudos em homenagem ao professor Doutor Marcello Caetano - No centenário de seu nascimento. Coimbra: Coimbra Editora, 2006.

ONU - Comitê DESC. Observação Geral nº 3, de 1990. Disponível em http://www.unhchr.ch/tbs/doc.nsf/(Symbol)/94bdbaf59b43a424c12563ed0052b664?Opendoc ument. Acesso em 27 jul. 2019.

ONU. Declaração Universal dos Direitos Humanos de1948. Disponível em http://portal.mj.gov.br/sedh/ct/legis_intern/ddh_bib_inter_universal.htm. Acesso em 04 ago. 2019.

ONU. Comitê DESC. Observação Geral no 12, de 1999. Disponível em http://www.unhchr.ch/tbs/doc.nsf/(Symbol)/3d02758c707031d58025677f003b73b9?Opendoc ument. Acesso em 28 jul. 2019.

ONU. Comitê DESC. Observação Geral nº 14, de 2000. Disponível em http://www.unhchr.ch/tbs/doc.nsf/(Symbol)/40d009901358b0e2c1256915005090be?Opendoc ument. Acesso em 27 jul. 2019.

ONU. Comitê DESC. Observação Geral no 15 , de 2002. Disponível em http://www.unhchr.ch/tbs/doc.nsf/0/a5458d1d1bbd713fc1256cc400389e94/\$FILE/G0340229. pdf. Acesso em 28 jul. 2019.

PES, João Hélio Ferreira. Água Potável: Direito fundamental de acesso, dever fundamental de fornecimento. Rio de Janeiro: Lumen Juris, 2019.

PES, João Hélio Ferreira. A constitucionalização de direitos humanos elencados em tratados. Ijuí: Editora Unijuí, 2010.

PINTO, Mauricio Esteban; TORCHIA, Noelia; MARTÍN, Liber. El derecho humano al agua: particularidades de su reconocimiento, evolución y ejercicio. Buenos Aires: AbeledoPerrot, 2008.

PIOVESAN, Flávia. Direitos humanos e o direito constitucional internacional. 9. a ed. rev., ampl. e atual. São Paulo: Saraiva, 2008.

Protocolo Facultativo do Pacto Internacional de Direitos Econômicos, Sociais e Culturais. Adotado pela Assembleia Geral das Nações Unidas de 10 de Dezembro de 2008, através da resolução A/RES/63/117. Disponível em http://direitoshumanos.gddc.pt/3_1/IIIPAG3_1_5.htm. Acesso em 02 ago. 2019. 
SARLET, Ingo Wolfgang. A eficácia dos direitos fundamentais. $10^{\mathrm{a}}$ edição, revista, atualizada e ampliada. Porto Alegre: Livraria do Advogado, 2010.

SARLET, Ingo Wolfgang. Valor de alçada e limitação do acesso ao duplo grau de jurisdição: Problematização em nível constitucional à luz de um conceito material de direitos fundamentais. In Revista de Informação Legislativa. Brasília a. 33 n. 131 jul./set. 1996.

SCHWARTZ, Germano André Doederlein. Direito à saúde: efetivação em uma perspectiva sistêmica. Porto Alegre: Livraria do Advogado, 2001.

SILVA, José Afonso da. Aplicabilidade das normas constitucionais. $3^{\text {a }}$ ed., São Paulo: Malheiros, 1985

SILVA, José Afonso da. Aplicabilidade das normas constitucionais.6 $6^{\mathrm{a}}$ ed., São Paulo: Malheiros, 2002.

SILVA, José Afonso da. Curso de direito constitucional positivo. $23^{\circ}$ ed. São Paulo: Melhoramentos, 2004.

TORRES, Ricardo Lobo. O direito ao mínimo existencial. Rio de Janeiro: Renovar, 2009.

TRINDADE, Antônio Augusto Cançado. Tratado de Direito Internacional dos Direitos Humanos. Vol. I. Porto Alegre: Sergio Antônio Fabris Editor, 1999. 